\title{
Analysis of the Implementation Mentorship Model as an Effort for Professionalism Attitude of Midwifery Undergraduate Students about Life Skill Midwife Profession
}

\author{
Yulizawati $^{1}$, Masrul ${ }^{2}$, Detty Iryani ${ }^{1}$, Rika Susanti ${ }^{3}$, Lusiana El Sinta Bustami ${ }^{1}$, Aldina Ayunda \\ Insani $^{1}$ \\ yulizawati@med.unand.ac.id \\ ${ }^{1}$ Bachelor of Midwifery Program Faculty of Medicine Andalas University Jln. Niaga no. 56 Padang, \\ Indonesia \\ ${ }^{2}$ Department of Nutrition, Faculty of Medicine, Universitas Andalas Padang, Indonesia \\ ${ }^{3}$ Division of Forensic and Medicolegal, Faculty of Medicine, Andalas University, Padang
}

\begin{abstract}
The importance of the attitude possessed by a health worker, especially a midwife, will have an impact on client satisfaction. Factors that influence the attitudes and behavior of health workers indicate to emphasize the health system, especially communication and counseling skills. The aim of this study is to determine the influence of implementation mentorship model as professionalism attitude of midwifery undergraduate students about life skill midwife profession. This was a quantitative study with quasiexperimental design using one group pretest-posttest by conducting initial tests before being given treatment in the form of mentorship models, after being given the mentorship models, tests are also carried out to assess student professional attitudes. This study conducted in Midwifery Undergraduate Study Program, Faculty of Medicine, Andalas University from June to December 2017. The data obtained will be analyzed using paired t-test. The analysis was carried out by McNemar test with $p$ value 0.016 meaning that there was a meaningful relationship in the application of mentorship models as an effort to increase the professionalism of Midwifery Undergraduate Study Program students about the midwife's life skill profession. The majority of student characteristics related to midwives' life skills after mentorship models are adaptive and have increased from $69.6 \%$ to $84.8 \%$. Most students have adaptive life skills. The majority of student characteristics related to midwife's professional life skills after mentorship models are adaptive and have increased. There are significant differences from the characteristics of students related to Midwife's professional life skills before and after the implementation of mentorship models.
\end{abstract}

Keywords: Mentorship Model, Professionalism Attitude, Life skill midwife profession

\section{Introduction}

The importance of the attitude possessed by a health worker, especially a midwife, will have an impact on client satisfaction. A review showed that various negative attitudes towards Maternal Health Care Providers affected client welfare and care satisfaction (ICM, 2013).

It was reported that more negative interactions occur rather than positive ones. As natural as possible, the factors that influence the attitudes and behavior of health workers indicate to emphasize the health system, the development especially communication and counseling skills. Greater attention is needed for attitudes and behavior in an effort to improve maternal and family health.( Cole, A. 2011).

Midwifery Undergraduate Study Program, Faculty of Medicine, Andalas University is one of study programs that conducts midwifery academic education at the strata level 1 . It is the only Bachelor Midwifery Study Program in Sumatra, Indonesia and the only one that applies problem-based learning methods. Established in 2013 after a year earlier was formed. 
The presence of candidates for the Midwifery Undergradute Program and Professional Midwives is highly expected to make the midwivery profession in Indonesia develop. Midwives from profession program are expected to be able to provide professional midwifery services for women, families and the community. Professional midwives are expected to be able to carry out their functions and duties according to their competence. Professional midwives are expected to have life skill characters that make themselves able to assist women throughout their life cycle.Mentoring is very important for the process of recruitment and retention of a qualified professional, career development, and the development of leadership traits (DOH, 2014).

This study aims to determine the influence of implementation mentorship model as professionalism attitude of midwifery undergraduate students about life skill midwife proffesion.

\section{Methods}

This was a quantitative study with quasi-experimental design using one group pretestposttest by conducting initial tests before being given treatment in the form of mentorship models, then after being given the menthorship models, tests are also carried out to assess student professional attitudes. This study conducted in Midwifery Undergraduate Study Program, Faculty of Medicine, Andalas University from June to December 2017. The data obtained will be analyzed using paired t-test.

\section{Result}

Characteristic Students about midwife professional skill before given Mentorship Model

Table 1. Characteristic student's life skill PreMentorship Model

\begin{tabular}{llll}
\hline \multicolumn{1}{c}{$\begin{array}{c}\text { Characteristic student's life skill PreMentorship } \\
\text { Model }\end{array}$} & f (n) & \% & Total \\
\hline Less Adaptive & 14 & 30,4 & 30,4 \\
Adaptive & 32 & 69,6 & 100 \\
Total & 46 & 100 & 100 \\
\hline
\end{tabular}

Before given Mentorship Model the students be given MMPI pshycologycal test to asses life skill midwifery proffesion. The results of univariate analysis of the characteristics of students related to midwife professional life skills before being given mentorship models showed that most students had adaptive life skills of $32(69.6 \%)$.

Characteristic Students about midwife professional skill after given Mentorship Model

After being given mentorship model for 2 weeks, students given MMPI pshycologycal test to asses life skill midwifery proffesion

Table 1. Characteristic student's life skill PostMentorship Model

\begin{tabular}{llll}
\hline $\begin{array}{l}\text { Characteristic student's life skill Post Mentorship } \\
\text { Model }\end{array}$ & f (n) & \% & Total \\
\hline less Adaptive & 7 & 15,2 & 15,2 \\
Adaptive & 39 & 84,8 & 100 \\
Total & 46 & 100 & 100 \\
\hline
\end{tabular}


The majority of student characteristics related to midwives' life skills after mentorship models are adaptive and have increased from $69.6 \%$ to $84.8 \%$

Comparison characteristic students about Life Skill Midwife Proffesion before and after being given Mentorship Model

Table 3. Comparisiin Characteristic Student

\begin{tabular}{lllll}
\hline Pre mentorship model & Post mentorship model & Total & p-value \\
\hline & Less adaptive & Adaptive & & \\
Less Adaptive & 7 & 7 & 14 & 0 \\
Adaptive & 0 & 32 & 32 & 0.016 \\
Total & 7 & 39 & 46 & \\
\hline
\end{tabular}

Bivariate analysis was carried out on the characteristics of students related to Midwife's professional life skills before and after being given a mentorship model.

The analysis was carried out by McNemar test with $\mathrm{p}$ value 0.016 meaning that there was a meaningful relationship in the application of mentorship models as an effort to increase the professionalism of Midwifery Undergradute Study Program students about the midwife's life skill. There are significant differences between before and after the implementation of the mentorship model. The majority of student characteristics related to midwives' life skills after mentorship models are adaptive and have increased from $69.6 \%$ to $84.8 \%$.

\section{Disscussion}

Characteristics of Students Regarding Midwife's Professional Life Skill Before being given the Mentorship Model

Before being given the mentorship model, students were given MMPI psychotest to assess the midwives' professional life skill. The results of univariate analysis of the characteristics of students related to midwife professional life skills before being given mentorship models showed that most students had adaptive life skills of 32 (69.6\%). The characteristics of students that already adaptive before being given the mentorship model relate to the values that each person has. This value also depend on the personal character and the surrounding environment. Different student backgrounds, different regions, and different entry points make the character of each student also different.

Characteristics of Students Regarding Midwife's Professional Life Skill After being given the Mentorship Model

The Mentorship model given to Midwifery Undergraduate Students is included in Formal Mentoring where the mentoring involves a structured approach and has a specific intention to gain experience from mentors who are expertise in their fields. Mentoring is a very valuable strategy which provides an environment for students towards reinforcement and gaining information from their mentors (Fisher M, Webb C. 2008). 
Comparison characteristic students about Life Skill Midwife Proffesion before and after being given Mentorship Model

Supportive relationships with mentors enable students to increase their ownership in the clinical environment and make them feel accepted as a professionals.

\section{Conclusion}

We fully aware about the limited midwifery study that addresses the benefits of mentorship models. In this study we has several other benefits:

a. Mentoring makes students feel their experiences in clinical world.

b. Besides developing professional characteristics and attitudes, mentoring also enhances clinical abilities, management, and student leadership.

c. Making the experience for students about how to make decision and how care for clients is done so it help them towards Professional program later on.

\section{References}

1. International of Midwives Confederation. 2013. Definition of the Midwives. The Netherlands. www.internationalmidwives.org.2014.Philosophy and Model of Midwifery

2. Cole, A. 2011. The Role Of Mentoring In College Access And Success. Washington: Institute for Higher Education Policy

3. Collington V. 2015. Enhancing the Preparation of Mentors and Supervisors in South London. UK: Health Education England

4. DOH. 2004. Mentoring for doctors; Signposts to current practice for career grade doctors. UK: Royal Colleges.

5. Fisher M, Webb C. 2008. What do midwifery mentors need? Priorities and impact of experience and qualification. Journal compilation@2008 Blackwell Publishing Ltd. Learning in Health and Social Care, 8, 1, 33-46 